\title{
Abundance and demography of a seasonal aggregation of zebra sharks Stegostoma fasciatum
}

\author{
Christine L. Dudgeon ${ }^{1, *}$, Michael J. Noad ${ }^{2}$, Janet M. Lanyon ${ }^{1}$ \\ ${ }^{1}$ School of Integrative Biology, and ${ }^{2}$ School of Veterinary Sciences, University of Queensland, St. Lucia, Queensland 4072, Australia
}

\begin{abstract}
Seasonal aggregations commonly occur in the marine environment where typically wide-ranging organisms come together to exploit temporary resources or find conspecifics for mating events. The zebra shark Stegostoma fasciatum is a demersal carpet shark that aggregates over the austral summer months in the coastal waters of southeast Queensland, Australia. This study employed photo-identification and mark-recapture methods over a $3 \mathrm{yr}$ period (2003 to 2006) to investigate the population size and structure of this aggregation. In total 327 individual zebra sharks were identified from 570 photographs. Numbered dart-tags on 15 zebra sharks were used to confirm that pigmentation patterns were unique and persistent in wild zebra sharks for up to $810 \mathrm{~d}$. Pollock's robust design resulted in an annual population estimate of 458 individuals (95\% CI $=298-618)$. The mean number of zebra sharks observed on a single day was 8 ( $\pm 8 \mathrm{SE})$ and the maximum number of zebra sharks seen on a single day was 34 . In total, $27 \%$ of the sharks were sighted in more than one summer aggregation period and males had greater re-capture probabilities than females. The aggregation consisted exclusively of large ( $>1800 \mathrm{~mm}$ total length) adults with an overall female sex bias of 3.8:1 though sex-ratios varied temporally. Predictable visitation of large, presumably mature individuals to the site raises conservation concerns if aggregations of similar size and structure occur in regions where zebra sharks are fished.
\end{abstract}

KEY WORDS: Mark-recapture - Seasonal aggregation - Zebra shark - Stegostoma fasciatum • Photo-identification · Abundance

\section{INTRODUCTION}

In the marine environment, wide-ranging organisms across a range of taxa frequently participate in seasonal aggregations. These include crustaceans (Osgood \& Checkley 1997, Sampedro \& GonzalezGurriaran 2004, Sourisseau et al. 2006), echinoderms (Young et al. 1992), teleosts (Domeier \& Colin 1997, Newlands et al. 2006), chondrichthyan fishes (Wilson et al. 2001) and cetaceans (Smith \& Martin 1994, Friedlaender et al. 2006). Animal aggregations, as defined by Allaby (2006), are groups of independent individuals that are attracted to an environmental resource, and lack social organisation. The attracting environmental resources may be driven by physical processes, e.g. oceanic structures (Friedlaender et al. 2006) or temperature (Hight \& Lowe 2007), or biological pro- cesses, e.g. feeding sites (Friedlaender et al. 2006) or spawning aggregations (Domeier \& Colin 1997).

Many chondrichthyan fish species form seasonal aggregations, whose proposed functions include mating (Castro \& Rosa 2005), foraging (Wilson et al. 2001, Meekan et al. 2006) and refuging (i.e. resting during the inactive diel phase: e.g. Nelson \& Johnson 1980, McKibben \& Nelson 1986, Semeniuk \& Dill 2005). Furthermore, sex and size segregation in aggregations are common, and have been found to be correlated with reproductive strategy (Klimley 1987, Economakis \& Lobel 1998, Sims et al. 2001, Hight \& Lowe 2007). Klimley (1987) found that sexual dimorphism and gender bias were more prevalent in viviparous than oviparous species, which may be due to females seeking either warmer waters to aid in gestation, or richer food sources to aid in growth for reproductive output. Sev- 
eral species show size segregation particularly in the use of juvenile nursery areas. These may provide refuge from larger predators as well as foraging grounds (Heupel \& Simpfendorfer 2005). Predictable aggregations may be of particular conservation concern if localised fishing can rapidly remove a large proportion of the population (Sadovy \& Domeier 2005). This concern is amplified if the aggregation comprises a large proportion of one life-history stage of the population. For example, aggregations of pregnant female piked dogfish Squalus acanthias have been targeted by fisheries (Compagno et al. 2005).

Predictable aggregations also lend themselves to mark-recapture studies where reasonably high recapture probabilities are required to estimate various demographic parameters (average recapture probabilities $\geq 0.1$; Otis et al. 1978). Such studies in sharks have focused primarily on size of aggregations (e.g. McLaughlin \& O'Gower 1971, Cliff et al. 1996, Strong et al. 1996), though mortality (Cliff et al. 1996) and survival (Bradshaw et al. 2007) have also been estimated. Photographs of natural markings for identifying individuals, termed photo-identification (photo-ID), from pioneering work on marine mammals (Hammond 1986) have been used in several shark species as the 'marking' method. These include white sharks Carcharodon carcharias (Domeier \& Nasby-Lucas 2007), whale sharks Rhincodon typus (Meekan et al. 2006, Speed et al. 2007), nurse sharks Ginglymostoma cirratum (Castro \& Rosa 2005) and grey nurse sharks Carcharias taurus (Van Tienhoven et al. 2007). Photo-ID methods have helped to circumvent some problems with conventional tagging such as tag loss and individual behavioural responses to restraining and tag insertion (capture heterogeneity; Minta \& Mangel 1989). However, the reliability of the method is speciesspecific: in the highly patterned whale sharks, the spotting patterns have been used to match individuals unambiguously with success spanning $12 \mathrm{yr}$ (Meekan et al. 2006) while in the less patterned nurse shark, only $46 \%$ of the observed sharks within an aggregation were identifiable based on natural markings (Castro \& Rosa 2005).

The zebra shark Stegostoma fasciatum is a mediumsized, demersal shark distributed within shallow, coastal, subtropical and tropical waters of the western Pacific and Indian Oceans (Compagno 2002). Zebra sharks are usually solitary, found resting on sandy substratum around coral and rocky reefs. However, they also form aggregations comprising 20 to 50 individuals (Pillans \& Simpfendorfer 2003). The shallow coastal water preference and formation of aggregations in zebra sharks makes them highly susceptible to direct and indirect capture from various fisheries and has resulted in their classification as 'Vulnerable' on the
IUCN Red List in parts of their range. In Australian waters, zebra sharks (known locally as leopard sharks) are not fished for consumption and are classified as 'Least Concern' (Pillans \& Simpfendorfer 2003).

This study focuses on an annual aggregation of zebra sharks that occurs over the austral summer months in the inshore coastal waters of southeast Queensland, Australia. As zebra sharks in this region are not fished, this aggregation provides an opportunity to investigate and calculate base-line population parameters, such as abundance and survival probabilities, for an unexploited population. Zebra sharks are part of the order Orectolobiformes, or carpet sharks, which is comprised mainly of benthic or demersal sharks as well as the pelagic whale shark. The juveniles of many orectolobiform sharks have strongly patterned body pigmentation (bars, saddles and spots) and most species undergo a large ontogenetic change in patterning which may reflect the different habitat use between juvenile and adult forms, particularly in benthic species (Dingerkus 1986). Adult zebra sharks are commonly encountered on shallow reefs $(<30 \mathrm{~m}$ depth), while juveniles tend to be found in deeper waters of greater than $50 \mathrm{~m}$ (Compagno 2002). Juvenile zebra sharks have bold stripes and saddle markings that start to break up at total length (TL) of around 500 to $900 \mathrm{~mm}$ (Compagno 2002). This variation in natural markings may lend itself to individual identification.

In this study we employed mark-recapture methods to estimate population abundance of zebra sharks in a seasonal aggregation. We combined conventional physical tagging and photo-ID to confirm the unique and persistent character of the pigmentation patterns for individual identification. Further we investigate the size and sex distribution of the aggregation and examined variation due to sex, capture heterogeneity, survey effort and temporary emigration with Pollock's robust design.

\section{MATERIALS AND METHODS}

Study site. During the austral summer, zebra sharks have been periodically observed at various subtropical coastal rocky reefs extending over $300 \mathrm{~km}$ from Wolf Rock $\left(25^{\circ} 55^{\prime} \mathrm{S}, 153^{\circ} 10^{\prime} \mathrm{E}\right)$ in southeast Queensland to Julian Rocks $\left(28^{\circ} 38^{\prime} \mathrm{S}, 153^{\circ} 38^{\prime} \mathrm{E}\right)$ in northern New South Wales, Australia (C. Bansemer, R. Pillans, H. Elek, S. Hartley pers. comm.). We focused this study on one reef, called 'The Group' $\left(27^{\circ} 23^{\prime} \mathrm{S}, 153^{\circ} 33^{\prime} \mathrm{E}\right)$, located approximately $500 \mathrm{~m}$ offshore from North Stradbroke Island, southeast Queensland (Fig. 1). This site was chosen because zebra sharks had been observed here with regularity (D. Bell pers. comm.), 


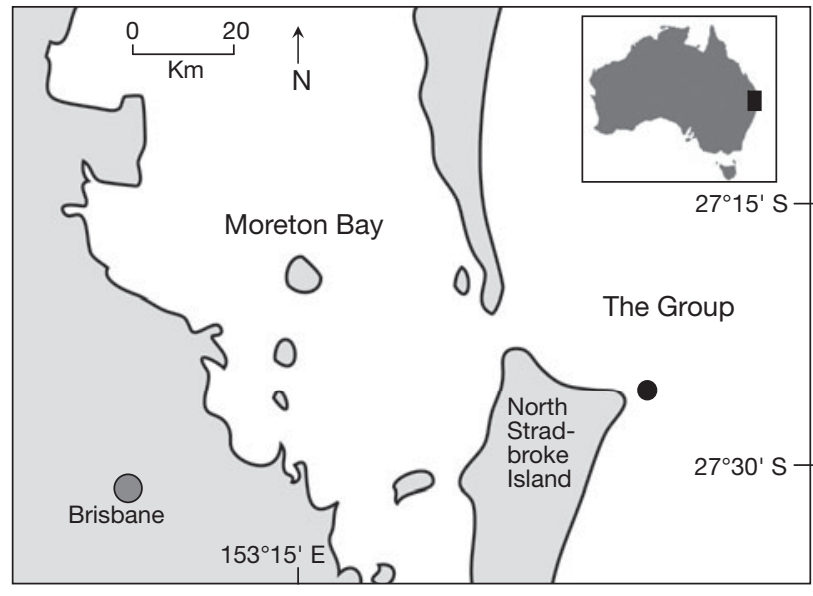

Fig. 1. Location of study site 'The Group' in southeast Queensland, Australia

the location is central to the distribution, and the site is readily accessible. The primary reef structure comprises a rock substratum with scattered sand patches covering an approximate area of $100 \times 50 \mathrm{~m}$ with depths ranging from $5 \mathrm{~m}$ to $18 \mathrm{~m}$. Zebra sharks are commonly found during daylight hours sitting on the sandy substratum facing into the prevailing southerly current (C. L. Dudgeon pers. obs.). Three other rocky reefs occur within a $4 \mathrm{~km}$ radius of The Group. One of these sites, Boat Rock, was not surveyed due to hazardous sea conditions hindering attempts at repeated surveys, and though we surveyed the other 2 sites, Flat Rock and Shag Rock, periodically during the study, zebra sharks were found in much smaller numbers $(0$ to 3 individuals at any one time) than at The Group.

Sampling approach. All surveys were conducted during the austral summer months (November to April in 2003-04 and 2004-05, and November to February in 2005-06). Surveys commenced immediately following reports from local dive tour operators of zebra sharks arriving at The Group. In the first 2 seasons, surveys were conducted into April of each year. However, because the numbers of sharks declined markedly during March and April, these months were pooled into the late season (February) sightings and not surveyed during the last year. During each month, multiple surveys (between 4 and 25) were conducted where each survey comprised a 40 min swim with SCUBA traversing a circuit following the multiple depth contours of the site.

Photo-ID and confirmation. During the first survey period, wild zebra sharks were photographed from all aspects to assess the most useful features for photo-ID. Preliminary observations suggested that the aggregation was comprised primarily of large zebra sharks with adult spotting patterns. We found the most variation in spotting patterns was on the first dorsal fin and lateral flank region from behind the gill slits extending caudally to the pelvic fins and we consequently focused on these regions (Fig. 2). Photographs of each swimming or resting shark encountered during surveys were taken with an Olympus C50 digital camera. Where possible, both sides of the shark were photographed, though as the sharks tend to orientate into the southerly current with the rock structure adjacent to their right side, the left side was often the most accessible and therefore all sharks in the study had left lateral photos taken. Photographs were also taken of any unusual body features including injuries and deformities and these were used to assist in individual identification. Photographs were matched by eye by 1 or 2 observers and double-checked by the primary investigator (C. L. Dudgeon).

As zebra sharks undergo a large ontogenetic change in marking patterns (Compagno 2002), consistency of individual markings over time was unknown. To confirm the use of natural markings for identification in wild zebra sharks, we applied numerically coded dart- (a) MBM5-Dec 2003

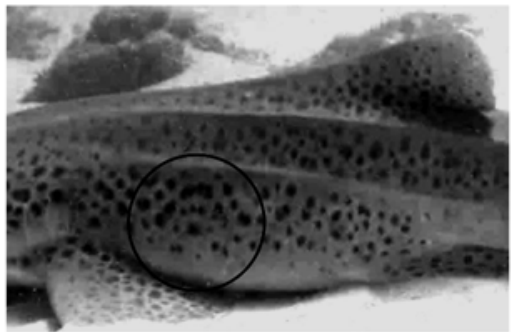

(c) MBF26-Jan 2004

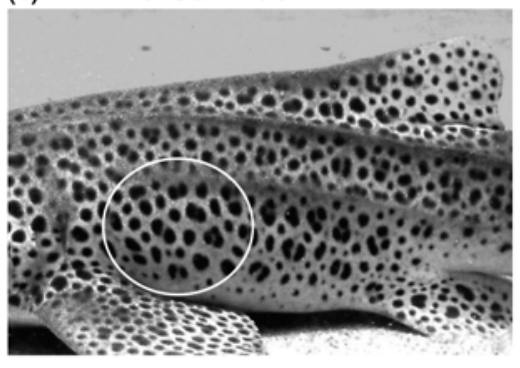

(b) MBM5-Feb 2006

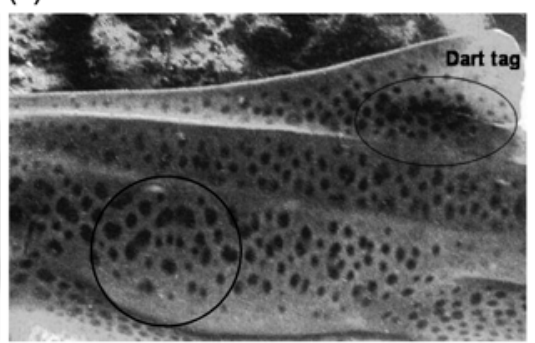

(d) MBF26-Feb 2006

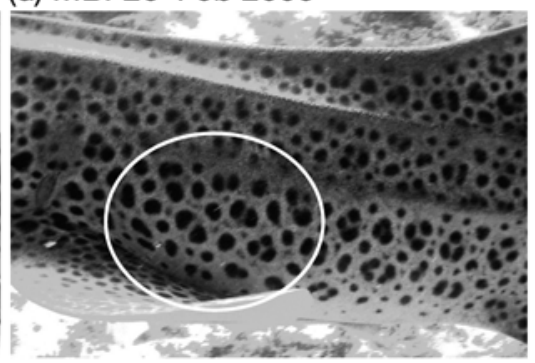

Fig. 2. Stegostoma fasciatum. Photo-ID patterns of 2 zebra sharks for: $(\mathrm{a}, \mathrm{b})$ shark with dart-tag and number validated, ID code = MBM5, (a) first sighting and (b) $810 \mathrm{~d}$ post-tagging and; $(\mathrm{c}, \mathrm{d})$ shark with dart-tag and number not validated, ID code = MBF26, at (c) first sighting and (d) $767 \mathrm{~d}$ post-tagging. Diagnostic spotting regions for photo-ID are highlighted. The fouled dart-tag is visible in photo (b), and was removed following this photograph ID for number validation 
tags (Hallprint) to 95 zebra sharks that were also photographed during the first 2 yr of the study. Darttags were inserted into the dorsal musculature at the base of the first dorsal fin of the shark while it rested on the substratum, and applied using a hand spear on a tagging pole by SCUBA divers. When sharks with dart-tags were re-sighted on subsequent surveys, photographs of the sharks were taken. If possible, the tag number was read in situ, however due to fouling on the tags it was necessary to remove the tags from some sharks to read the numbers for photo-ID confirmation.

Further, there were 2 individuals (1 male and 1 female) that had cattle ear tags inserted through the dorsal fins during a prior study conducted at The Group in November 2000 (D. Bell pers. comm.). These sharks were photographed during the course of our study and incorporated into the data set. For the male shark, we obtained an archival photograph from December 2000, shortly after the tagging event, that we were able to photo match and use for photo-ID confirmation

Size measurements and sex identification. TL of sharks resting on the substratum was estimated by taking a photograph of the entire shark from a dorsal aspect (in line with the first dorsal fin). A tagging pole of known length and width placed on the substratum parallel and adjacent to the shark was used to calibrate the digital ruler for taking measurements from the photograph using the software Matrox Inspector 2.1 (Matrox Electronic Systems). For 5 individuals, TL was measured in situ with a tape measure to compare the estimates from the photographs. Further multiple photographs of the same individuals within seasons and between seasons were measured to obtain variation in length estimates using the photographic technique. Size differences between male and female sharks and between new and re-sighted sharks per season were analysed using $t$-tests. Sharks were sexed visually by looking for the presence of claspers that are found only in males (Last \& Stevens 1994). Temporal effects in observed sex-ratio were analysed by constructing a series of binomial generalised linear models (GLM) with a logit-link function, implemented in the $\mathrm{R}$ Package (R Development Core Team 2004). The fixed factors of (1) Year and (2) Month were compared to the null model (underlying distribution not including factors). The additive and interaction effects (3) Year + Month and (4) Year $\times$ Month were assessed using a stepwise approach and the significance of the added factor was evaluated at the $5 \%$ error level using the $\chi^{2}$ test.

Abundance estimates and population modelling. Annual estimates of population size for male and female zebra sharks aggregating at The Group during 2003 to 2006 were derived using Pollock's robust design (Pollock et al. 1990, Kendall et al. 1995) implemented in the program MARK v. 4.3 (White \& Burn- ham 1999). Pollock's robust design model combines 2 levels of sampling: primary periods and secondary samples nested within the primary periods. Primary periods are those that are separated from each other by sufficient time to allow for change in the population through gains and losses (Kendall 1997). For this study, the 3 summer field seasons (2003-04, 2004-05, 2005-06) were treated as the primary periods, allowing the population to be demographically open between years. Conversely, secondary samples are separated by short enough amounts of time to consider the population as demographically closed (Kendall 1997). The 4 mo within each field season (November to February) were treated as secondary samples with intervals ranging between 9 and $33 \mathrm{~d}$.

The robust design calculates the following parameters: apparent annual survival $\varphi$ (i.e. probability that a shark is alive and available for re-capture, herein referred to as survival), temporary emigration $\gamma$ (the probability of not being available for capture given the individual is alive), capture probability $\mathrm{p}$, and abundance $\tilde{N}$ (Pollock et al. 1990). There are several advantages to using the robust design. First, abundance and survival parameter estimates are robust to capture heterogeneity (individual differences in capture probabilities). The Cormack-Jolly-Seber (CJS) open population model (Cormack 1964, Jolly 1965, Seber 1965), that calculates survival and recapture probabilities, is robust to capture heterogeneity in survival estimates and within the robust design is used to estimate survival probability among primary periods. Closed population models are more robust than CJS models to heterogeneity in abundance estimates and are therefore used in the robust design to estimate abundance across secondary samples within primary periods. Second, all parameters can be estimated; in contrast, there are several parameters in Jolly-Seber (JS) models, open population models that include abundance estimation, that cannot be estimated due to confounding. Third, individual covariates can be incorporated into the model to allow for greater data maximisation (Kendall \& Pollock 2001).

Assumptions of the parameter estimations for the robust design are: (1) all zebra sharks possess unique markings and these marks are stable over time; $(2)$ the population is closed to additions (birth and immigration) and deletions (death and emigration) within each primary period; (3) survival probability is equal for all sharks within each sex among primary periods.

Huggins's closed model estimator (Huggins 1989) was used to derive population size as this estimator is robust to small samples sizes and allows for individual covariates to be incorporated into the model. Difference in survival $\varphi$ between male and female sharks was assessed by modelling constant (.) and annual time varying $(t)$ survival probability between the 3 pri- 
mary periods both with and without sex $(g)$ effects: $\varphi(g), \varphi(),. \varphi(t), \varphi(g+t)$.

Temporary emigration $(\gamma)$ may negatively bias survival and capture probabilities and introduce positive bias into abundance estimates (Williams et al. 2002). The extent that temporary emigration among primary sampling periods influenced the estimate of population size was assessed through 3 models: (1) no temporary emigration $\gamma(0)$; (2) random temporary emigration $\gamma(\operatorname{Ran})$; and (3) random temporary emigration with sex effect $\gamma(g+$ Ran $)$.

Effects on capture probability due to sex, survey effort and individual heterogeneity were assessed using the method of Bradford et al. (2006). Specifically, survey effort was incorporated into the model as a time-covariate, efficiency (Eff), as the number of survey dives conducted per month. Capture heterogeneity can arise if some individuals spend more time in the study area within a secondary sample (month) than others and are therefore more likely to be sighted (Buckland 1990). Individual zebra sharks were sighted within sampling months between 1 and 5 times. To account for this variation an individual covariate, residency (Res), was calculated for each zebra shark as: the number of survey dives in a given month that an individual is observed divided by the mean number of survey dives in that month of all individuals that were observed, averaged across all months in which the individual shark was observed. Trends over time $(T)$ were also assessed where support for models incorporating $(T)$ indicated an increase in recapture probability over time due to increased observer experience. Eighteen capture probability models combining variation in sex $(g)$, time constrained (.) or varying by secondary samples $(t)$, trend over time $(T)$, survey effort (Eff) and residency (Res) were assessed. In total, 63 different models combining the survival, temporary emigration and capture probability models were fitted with the logit link function for all parameters. Not all combinations of the temporary emigration parameters were possible and these models were not included in the final list. The most parsimonious model, $\varphi(.) \lambda(g+t) \mathrm{p}(g+t)$, was also modelled incorporating the parameter $\lambda$, the population rate of change, with the Pradel model in the robust design, where $\lambda<0$ indicates a decrease, $\lambda=0$ indicates stasis and $\lambda>0$ indicates an increase in population size (Pradel 1996).

To assess potential violation of the closure assumption within the primary periods, we applied the JS open population model, collapsing the data over the 3 primary periods. The JS modelling was implemented in program MARK v. 4.3 (White \& Burnham 1999) using the POPAN option (Schwarz \& Arnason 1996). Four variations on apparent survival were modelled as for the robust design: $\varphi(g), \varphi(),. \varphi(t), \varphi(g+t)$. Recapture probability was modelled as a constant variable with and without sex effect, $\mathrm{p}(g)$ and $\mathrm{p}($.$) , respectively, to$ eliminate any confounding in the estimation of survival and abundance parameters (Schwarz \& Arnason 1996). The probability of entry $(\beta)$ was modelled as time variant without sex effect. In total, 8 models were fitted using the logit link function for $\varphi$ and $p$, the identity link function for abundance $(\tilde{N})$, and the multinomial logit link function for $\beta$. The assumptions of the JS model are as for the robust design though the population is demographically open between sampling periods and sampling is considered to be instantaneous (Pollock et al. 1990). Further, to assess potential bias in survival estimates due to inestimable or poorly estimated parameters in the robust design, the 4 variations on apparent survival $\varphi$ for the 3 yr collapsed data set were also modelled with the simplified CJS model (Cormack 1964, Jolly 1965, Seber 1965). Recapture probability was modelled as time variant with sex effect $\mathrm{p}(g+t)$.

Model support was assessed using Akaike's information criterion for small samples (AICc). Final population size and survival parameter estimates were obtained by model averaging to include model variation into the precision of the estimates, and relative variable importance was assessed by summing the Akaike weights (AICC) across the model set (Burnham \& Anderson 2002).

\section{RESULTS}

\section{Photo-ID and confirmation}

In total, 570 photographs of 327 individual sharks were taken during the course of the study. The maximum number of individual sharks observed on any $1 \mathrm{~d}$ was $34(8 \pm 8$, mean $\pm \mathrm{SE})$. In total, 115 sharks were recaptured on up to 10 sampling days throughout the study $(2.90 \pm 0.14$ sampling days). Within the austral summer seasons, sharks were captured up to 7 times $(1.57 \pm 0.06$ sampling days). The mean recapture duration for within seasons was $33 \mathrm{~d}( \pm 30)$ with the longest duration between first and last capture of $136 \mathrm{~d}$. A total of 236 individual sharks were sighted in only 1 season, while 79 were sighted in 2 seasons and 8 sighted in all 3 seasons.

There was no ambiguity with matching photographs by eye; all marks on the lateral flank and dorsal fin were matched before a photograph was considered a definite re-sight. Of the photographed sharks, 95 had numerically coded dart-tags. The numbers on 15 darttags were read ( 3 while on the shark and 12 after being removed) to confirm photographic matches between 354 and 810 d post-tag deployment (see Fig. 2). We 
were able to match photographs taken in this study of one male fin-tagged shark with the archival photograph from December 2000 spanning 1469 d (4 yr). Further, another 24 sharks with dart-tags were matched by photographs between 7 and $772 \mathrm{~d}$ post deployment (Fig. 3). However, due to fouling on these tags, the numbers were not read for confirmation, though the pigmentation patterns showed clear and unambiguous matches between the photographs. It was possible to match photographs to all re-sighted sharks with dart-tags. There were 8 confirmed dart-tag losses where individuals were matched by photo-ID. Of these, sharks were sighted with tags missing between 53 and $744 \mathrm{~d}$ post-deployment. The duration of tag retention before shedding is unknown. After the tagging event, $48(51 \%)$ of the dart-tagged sharks were not sighted again. This is unlikely to be a reaction to dart-tagging as $65 \%$ of the sharks identified solely through photo-ID from the first 2 seasons were also not sighted again during the third season of the study.

\section{Size distribution}

TL of 79 zebra sharks (28 males and 51 females) pooled across the 3 sampling seasons was measured from photographs. It was not possible to measure TL for the rest of the sharks due to either the shark moving before the dorsal photograph could be taken, or if the angle of the photograph was too skewed. Sharks ranged from 1875 to $2460 \mathrm{~mm}$ in TL and there was no significant difference between the sexes (2-tailed $t$-test: $t=-0.5, \mathrm{df}=60, \mathrm{p}=0.618$ ) (Fig. 4). Of the $65 \mathrm{ze}$ bra sharks measured from the second and third field season, 12 were sighted in a previous field season and 53 were sighted for the first time. There was no evidence of smaller recruits entering the population as the re-sighted animals were found to be significantly

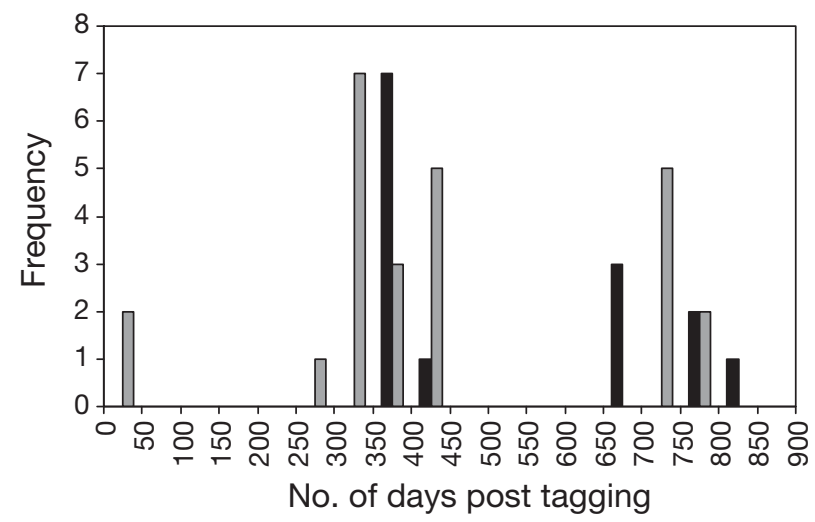

Fig. 3. Stegostoma fasciatum. Frequency of duration of tag validation with tag number read and confirmed (black bars) and tag number not read but tag visible on zebra sharks (grey bars)

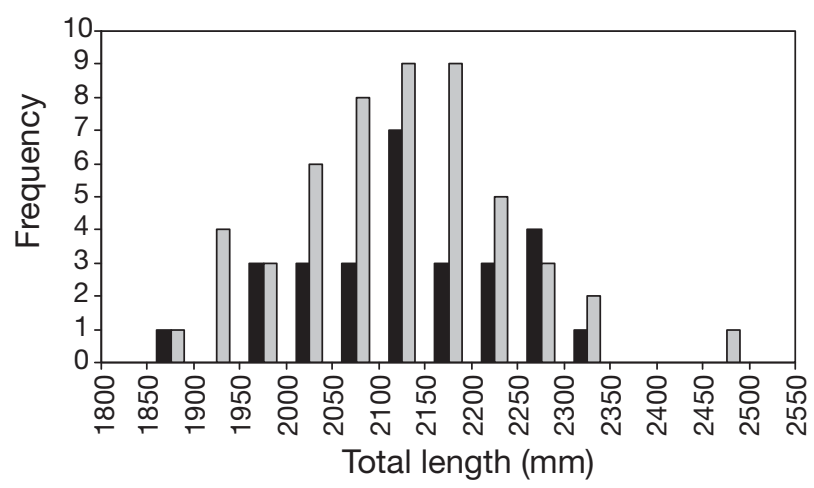

Fig. 4. Stegostoma fasciatum. Total length distribution for male (black bars, $\mathrm{n}=28$ ) and female (grey bars, $\mathrm{n}=51$ ) zebra sharks pooled over 3 sampling seasons

smaller, though this is likely due to differences in sample size (1-tailed $t$-test: $t=2.51, \mathrm{df}=26, \mathrm{p}=0.009$ ). For 5 sharks there was approximately $2.4 \%$ variation from average TL for within-season photographs $(\mathrm{n}=5$, $50 \pm 38 \mathrm{~mm}$, mean $\pm \mathrm{SE}$ ), $5.7 \%$ variation from the average TL from among season photographs $(n=7,118 \pm$ $85 \mathrm{~mm})$, and $4.8 \%$ variation between the tape measure and photograph TL estimates $(\mathrm{n}=5,101 \pm 102 \mathrm{~mm})$. This level of variation suggests that photographic measurement is sufficient for estimating TL in wild zebra sharks though may not be precise enough for investigating small increments in growth.

\section{Sex ratio}

In total, 86 male and 241 female zebra sharks were identified by photo-ID resulting in an overall female bias of 2.8:1. The overall sex ratio based on the population size estimates from the mark-recapture modelling for 2005-06 also supported a female bias of 3.8:1. The GLM analysis showed that Month had the greatest effect of the sex-ratio probability while Year was not

Table 1. Stegostoma fasciatum. GLM analysis of fixed effects Year and Month on observed sex-ratio probability. df $=$ degrees of freedom; $\Delta$ Deviance $=$ additional amount of variation explained by adding the effect into the model (comparative model in brackets); $\mathrm{p}=$ significance of the chi-sq test, with comparative model in brackets

\begin{tabular}{|lrrcc|}
\hline Model & df & Deviance & $\Delta$ Deviance & $p\left(\chi^{2}\right)$ \\
\hline Null & 11 & 55.55 & - & \\
$(1)+$ Year & 10 & 53.88 & 1.67 (null) & 0.20 (null) \\
$(2)+$ Month & 8 & 13.14 & 42.41 (null) & 0.00 (null) \\
$(3)+$ Month +Year & 7 & 9.63 & $3.51(2)$ & $0.06(2)$ \\
$(4)+$ Month $\times$ Year & 4 & 2.98 & $6.65(3)$ & $0.08(3)$ \\
\hline
\end{tabular}


significant, nor was there a significant interaction effect (Table 1). A post-hoc Tukey's test showed that the Month effect was due to November, which was male biased, while December, January and February were all female biased (Fig. 5), and the absence of the interaction effect suggests that this pattern was consistent across the 3 yr.

\section{Abundance estimates and population modelling}

The robust design model list comprised 63 models of which 17 models demonstrated information-theoretic support (Table 2: sum of AICc weights $=1$; complete list in Appendix 1). There was little variation attributable to model selection for male and female population estimates for the primary periods ( 0.19 to $2.64 \%$ ) (Table 3). With the exception of the male estimates for the period 2003-04, the population estimates decreased over time. Further, the confidence intervals narrowed over time, indicating more stability and precision in the estimates. The population rate of change parameter $\lambda$ indicated an increase in population size for both males and females between the first and second primary sampling periods during 2004, and then stability in population size between the second and third primary sampling periods during 2005 (male 2004: $\lambda=1.71, \pm 0.45[\mathrm{SE}] ;$ male 2005: $\lambda=0.98, \pm 0.16$; female 2004: $\lambda=1.71 \pm 0.45$; female 2005: $\lambda=$ $0.76 \pm 0.13)$. Based on the final primary sampling period 2005-06 and averaging over the 17 models, the population estimates for males and females (respectively) forming the aggregation at The Group each year were $96( \pm 17$, $95 \%, C I=62-130)$ and $368( \pm 62,95 \%$, $\mathrm{CI}=245-490)$. The JS model list comprised 8 models all demonstrating information-theoretic support (Table 2). Mean population estimates spanning 2003 to 2006 for both male and female zebra sharks are greater than for the annual robust design estimates: 125 $( \pm 15,95 \% \mathrm{CI}=95-153)$ and $469( \pm 46$, $95 \% \mathrm{CI}=379-559)$, respectively. The JS male and female estimates had higher variation attributable to model selection than the robust design: $28.3 \%$ and $8.76 \%$, respectively.

Models incorporating time constant and equal survival probability between

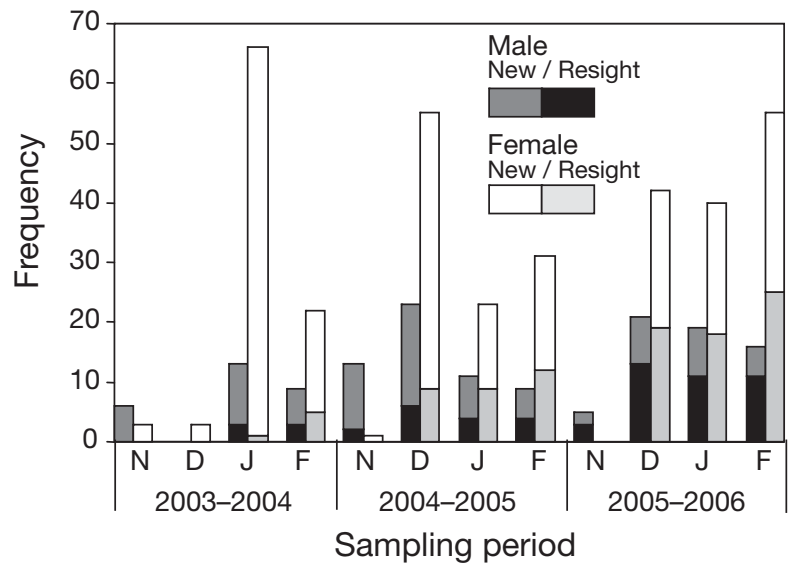

Fig. 5. Stegostoma fasciatum. Frequency of new and resighted male and female zebra sharks for each secondary sampling occasion; $\mathrm{N}=$ November, $\mathrm{D}=$ December, $\mathrm{J}=$ January, $\mathrm{F}=$ February

Table 2. Stegostoma fasciatum. Comparison of models from the robust design (RD: $\mathrm{n}=17$ ), Jolly-Seber (JS: $\mathrm{n}=8$ ) and Cormack-Jolly-Seber $\left(\mathrm{CJS}_{;} \mathrm{n}=4\right.$ ) models used to estimate abundance and survival parameters, AICC $=$ Akaike information criterion for small samples; delta AICc $=$ difference in the AICc of a model from the minimum AICc model; $\mathrm{AICc}$ weight $=$ Akaike weight used in model averaging; $\varphi=$ apparent survival; $\gamma=$ temporary emigration; $\mathrm{p}=$ capture probability; $()=$. time constant; $t=$ time varying by secondary sample; $g=$ sex; Ran $=$ random temporary emigration; $0=$ no temporary emigration; Res = residency; $\beta=$ probability of entry

\begin{tabular}{|c|c|c|c|c|c|}
\hline Analysis & Model & $\mathrm{AICc}$ & $\begin{array}{l}\text { Delta } \\
\text { AICc }\end{array}$ & $\begin{array}{c}\text { AICc } \\
\text { weight }\end{array}$ & $\begin{array}{c}\text { No. para- } \\
\text { meters }\end{array}$ \\
\hline \multirow[t]{17}{*}{$\mathrm{RD}$} & $\varphi(.) \gamma(0) \mathrm{p}(g+t)$ & 1730.38 & 0.00 & 0.36678 & 16 \\
\hline & $\varphi(g) \gamma(0) \mathrm{p}(g+t)$ & 1732.40 & 2.02 & 0.13369 & 17 \\
\hline & $\varphi(.) \gamma(\operatorname{Ran}) \mathrm{p}(g+t)$ & 1732.48 & 2.10 & 0.12819 & 17 \\
\hline & $\varphi(t) \gamma(0) \mathrm{p}(g+t)$ & 1732.48 & 2.10 & 0.12813 & 17 \\
\hline & $\varphi(g+t) \gamma(0) \mathrm{p}(g+t)$ & 1734.42 & 4.04 & 0.04858 & 18 \\
\hline & $\varphi(g) \gamma(\operatorname{Ran}) \mathrm{p}(g+t)$ & 1734.50 & 4.12 & 0.04667 & 18 \\
\hline & $\varphi(.) \gamma(0) \mathrm{p}(g+t+R e s)$ & 1734.58 & 4.20 & 0.04500 & 19 \\
\hline & $\varphi(.) \gamma(g+\operatorname{Ran}) \mathrm{p}(g+t)$ & 1734.61 & 4.23 & 0.04428 & 18 \\
\hline & $\varphi(g) \gamma(0) \mathrm{p}(g+t+R e s)$ & 1736.43 & 6.05 & 0.01782 & 20 \\
\hline & $\varphi(t) \gamma(0) \mathrm{p}(g+t+R e s)$ & 1736.54 & 6.16 & 0.01688 & 20 \\
\hline & $\varphi(g) \gamma(g+R a n) \mathrm{p}(g+t)$ & 1736.63 & 6.25 & 0.01610 & 19 \\
\hline & $\varphi(g+t) \gamma(0) \mathrm{p}(g+t+R e s)$ & 1738.44 & 8.06 & 0.00651 & 21 \\
\hline & $\varphi(.) \gamma(0) \mathrm{p}(t)$ & 1742.91 & 12.53 & 0.00070 & 13 \\
\hline & $\varphi(t) \gamma(0) p(t)$ & 1744.67 & 14.28 & 0.00029 & 14 \\
\hline & $\varphi(.) \gamma(\operatorname{Ran}) \mathrm{p}(t)$ & 1745.02 & 14.64 & 0.00024 & 14 \\
\hline & $\varphi(.) \gamma(0) \mathrm{p}(t+R e s)$ & 1746.99 & 16.60 & 0.00009 & 16 \\
\hline & $\varphi(t) \gamma(0) \mathrm{p}(t+\operatorname{Res})$ & 1748.82 & 18.44 & 0.00004 & 17 \\
\hline \multirow[t]{8}{*}{ JS } & $\varphi(.) \beta(t) \mathrm{p}(g)$ & 452.66 & 0.00 & 0.28207 & 7 \\
\hline & $\varphi(t) \beta(t) \mathrm{p}(g)$ & 452.95 & 0.29 & 0.24395 & 8 \\
\hline & $\varphi(g) \beta(t) \mathrm{p}(g)$ & 454.03 & 1.37 & 0.14207 & 8 \\
\hline & $\varphi(g+t) \beta(t) \mathrm{p}(g)$ & 454.55 & 1.90 & 0.10928 & 10 \\
\hline & $\varphi(g) \beta(t) \mathrm{p}()$. & 454.67 & 2.01 & 0.10304 & 7 \\
\hline & $\varphi(g+t) \beta(t) \mathrm{p}()$. & 455.48 & 2.82 & 0.06882 & 9 \\
\hline & $\varphi(t) \beta(t) \mathrm{p}()$. & 457.17 & 4.51 & 0.02952 & 7 \\
\hline & $\varphi(.) \beta(t) p()$. & 457.83 & 5.17 & 0.02125 & 6 \\
\hline \multirow[t]{4}{*}{ CJS } & $\varphi(.) \mathrm{p}(g+t)$ & 405.99 & 0.00 & 0.46408 & 4 \\
\hline & $\varphi(g+t) p(g+t)$ & 407.77 & 1.78 & 0.19067 & 5 \\
\hline & $\varphi(t) \mathrm{p}(g+t)$ & 407.96 & 1.97 & 0.17313 & 5 \\
\hline & $\varphi(g) \mathrm{p}(g+t)$ & 407.96 & 1.98 & 0.17212 & 5 \\
\hline
\end{tabular}


Table 3. Stegostoma fasciatum. Population abundance estimates of female and male zebra sharks; weighted averages across 17 robust design (RD) models and 8 Jolly-Seber (JS) models. Unconditional SE = standard error estimate that is not conditional on a particular model $; 95 \% \mathrm{CI}=$ confidence intervals for the weighted average estimates based on the logit transformation; \% Variation = variation in the estimate attributable to the model uncertainty

\begin{tabular}{|lrrrrrr|}
\hline Sex & Analysis & Year & $\begin{array}{c}\text { Weighted } \\
\text { average }\end{array}$ & $\begin{array}{c}\text { Uncond. } \\
\text { SE }\end{array}$ & $\begin{array}{c}\text { 95\% CI } \\
\text { (Weighted } \\
\text { average) }\end{array}$ & $\begin{array}{c}\% \\
\text { Variation }\end{array}$ \\
\hline Male & RD & $2003-04$ & 35.99 & 7.80 & $20.69-51.29$ & 2.42 \\
& & $2004-05$ & 117.45 & 25.16 & $68.13-166.77$ & 0.93 \\
& & $2005-06$ & 95.91 & 17.45 & $61.70-130.12$ & 2.28 \\
Female & JS & $2003-06$ & 123.90 & 14.90 & $94.70-153.11$ & 28.30 \\
& RD & $2003-04$ & 398.92 & 158.50 & $88.28-709.56$ & 0.19 \\
& & $2004-05$ & 387.92 & 79.19 & $232.71-543.14$ & 1.67 \\
& JS & $2005-06$ & 367.72 & 62.45 & $245.32-490.11$ & 2.64 \\
& $2003-06$ & 469.04 & 46.06 & $378.75-559.33$ & 8.76 \\
\hline
\end{tabular}

the sexes were well supported in the robust design model selection (Table 2: sum of Akaike weights for $\varphi()=$.0.582 ). Both male and female zebra sharks showed high survival probabilities and the weighted average estimates, respectively, were $0.888( \pm 0.105$ [SE], $95 \% \mathrm{CI}=0.497-0.984, \%$ variation attributable to model $=3.11)$ and $0.871( \pm 0.099,95 \%$ CI $=$ $0.544-0.975, \%$ variation attributable to model $=0.15$ ).

Time constant and equal survival probability between the sexes was also supported by the CJS model selection (Table 2: Akaike weight for $\varphi()=$.0.464 ) and the weighted survival estimates were similar to those of the robust design (male: $\varphi=0.866 \pm 0.143,95 \% \mathrm{CI}=$ $0.364-0.987, \%$ variation attributable to model $=1.33$; female: $\varphi=0.892 \pm 0.139,95 \% \mathrm{CI}=0.326-0.992$, $\%$ variation attributable to model $=1.47$ ).

Models incorporating no temporary emigration between primary periods had more support than either random temporary emigration with or without group effect (Table 2: sum of Akaike weights for $\gamma(0)=0.706$; $\gamma(\operatorname{Ran})=0.219 ; \gamma(g+\operatorname{Ran})=0.076)$.

Variation in capture probability by secondary samples was supported by all of the 17 robust design's most parsimonious models. This may be largely attributable to the low numbers of zebra sharks encountered during November of each season and also to the absence of male sharks in December 2003 and female sharks in November 2005 (Fig. 6). Difference in capture probability between male and female zebra sharks was very well supported (Table 2: sum of Akaike weights $=0.999$ ). Male sharks tended to have greater capture probabilities than female sharks. Based on the weighted averages for population size in 2005 to 2006 (Table 3) approximately $88 \%$ of male zebra sharks visiting The Group had been tagged as opposed to $67 \%$ of females. Individual sharks were sighted between 1 and 5 times within a month, how- ever there was little support for variation in capture probability due to this individual heterogeneity, Res (Table 2: sum of Akaike weights $=0.041$ ). There was no support for variation in capture probability due to survey effort, Eff, though monthly survey effort varied between 4 and 25 surveys, nor were linear trends in capture probability supported, suggesting reasonably consistent observer ability.

\section{DISCUSSION}

\section{Population description}

Here we present the first empirical abundance estimates of an aggregation of zebra sharks. Our mark-recapture assessments estimated 458 individuals (robust design: $95 \% \mathrm{CI}=298-618$ ) visiting The Group over the last survey year. This estimate is considerably larger than for zebra shark aggregations of 20 to 50 individuals as suggested in the literature (Pillans \& Simpfendorfer 2003). It is likely that these published estimates are of sharks seen at any one time and are more comparable to the daily counts of up to 34 individuals that we obtained. This raises the question as to the extent of the aggregation at The Group in space and time. Individual zebra sharks were observed up to 136 d later within the same survey season and the much smaller numbers of zebra sharks at neighbouring reefs (within $4 \mathrm{~km}$ radius) suggests that The Group is likely to be the core area of a larger aggregation site that the zebra sharks are moving in and out of during the austral summer aggregation season.

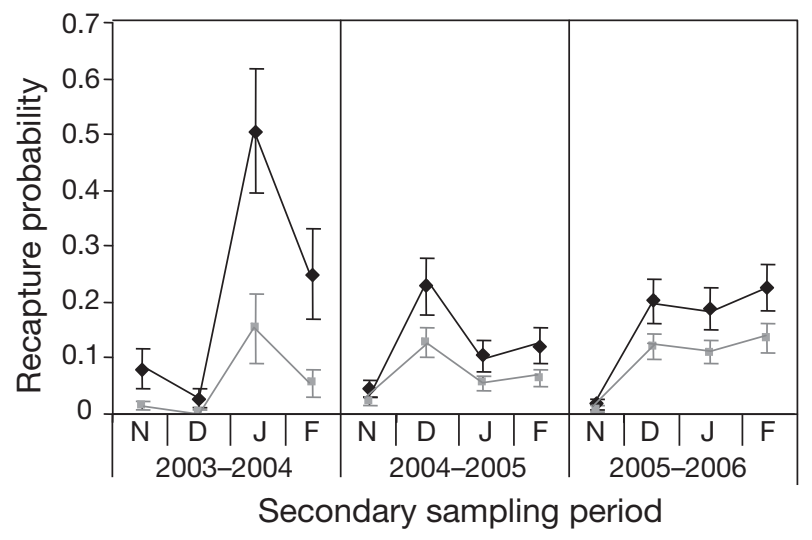

Fig. 6. Stegostoma fasciatum. Male (•) and female ( $\square$ ) capture probabilities with SE for secondary sampling occasions, taken from the best fit model $\varphi(.) \gamma(0) p(g+t) ; \mathrm{N}=$ November, $\mathrm{D}=\mathrm{De}-$ cember, $\mathrm{J}=$ January, $\mathrm{F}$ = February 
Zebra sharks in Australian waters are not exploited (Pillans \& Simpfendorfer 2003) and the patterns of population growth and stability of the population estimates between the first and second primary periods and second and third primary periods respectively, may reflect this. However, this initial pattern of population growth may also be an effect of increased observer ability (Dinsmore et al. 2005) and would need to be qualified by extending the study longitudinally. The absence of temporary emigration among primary periods indicates that individuals are returning to the aggregation site annually and that this pattern is the same for both sexes. Population size and dynamics at other aggregation sites for this species have not yet been assessed. However, populations that are continually exploited are more likely to show a decrease in population size over time. Predictable aggregations may be of particular conservation concern as fishing can rapidly remove large numbers of the population, especially if the aggregations comprise a greater proportion of the population than thought (Sadovy \& Domeier 2005).

Mark-recapture methods have been used to estimate population size in other shark aggregations including hammerhead sharks Sphyrna lewini (Clarke 1971), whale sharks (Meekan et al. 2006), nurse sharks (Castro \& Rosa 2005), white sharks (Cliff et al. 1996) and horn sharks Heterodontus portusjacksoni (McLaughlin \& O'Gower 1971). With the exception of the juvenile hammerhead sharks whose population estimates numbered in the order of thousands (Clarke 1971), the remaining estimates are comparable to the zebra shark estimates in the order of a few to several hundred individuals. Caution must be taken when comparing aggregation sizes however as various factors must be taken into account, including the geographic extent from which a particular aggregation site draws individuals, as well as its function, which in turn relates to the ecological niche of the species and life-history stages comprising the aggregation.

Many sharks display migratory behaviour and conventional tagging studies on coastal demersal shark species have revealed movements of hundreds of $\mathrm{km}$ (e.g. horn shark 400 km, McLaughlin \& O'Gower 1971; lemon shark $426 \mathrm{~km}$, nurse shark $541 \mathrm{~km}$, Kohler \& Turner 2001). Zebra sharks are likely to travel similar distances, as 2 zebra sharks with dart-tags inserted during this study have been sighted at Julian Rocks in New South Wales, $140 \mathrm{~km}$ south of the primary study site (S. Hartley pers. comm.). Further, adult zebra sharks have been sighted occasionally at Osprey Reef, an isolated sea mount in the Coral Sea (R. Fitzpatrick pers. comm.), indicating that although they prefer shal- low coastal environments, they do move into pelagic waters.

Many shark species segregate by size and sex. The zebra sharks comprising this aggregation appear to be all reproductively mature adults as TL ranged from 1875 to $2460 \mathrm{~mm}$ and zebra sharks reach sexual maturity at TLs between 1470 and $1830 \mathrm{~mm}$ for males and 1690 and $1717 \mathrm{~mm}$ for females (Compagno 2002). Klimley's (1987) sexual dimorphism hypothesis predicts that oviparous species, such as the zebra shark, do not have sexual dimorphism in body size and our TL data for male and female zebra sharks supports this. We found an overall female bias in the aggregation, though the sex bias changed temporally with more males at the beginning of the aggregation season, reversing to a female bias for the duration. Similar temporal changes in sex ratio have been found in the demersal horn shark and nurse shark and have been associated with the breeding season (McLaughlin \& O'Gower 1971, Castro \& Rosa 2005). On 2 occasions we observed possible pre-copulatory following behaviour (Gordon 1993), where a male was closely following a female while slowly swimming around the site. Further, we found that male zebra sharks had higher recapture probabilities than females which may indicate greater philopatry in males. Philopatry has been observed in other shark species though has generally been more biased towards the female sex, particularly in species that utilise nursery areas (see Hueter et al. 2005). Pratt \& Carrier (2001), however, found male nurse sharks showed greater philopatry than females as males returned annually to a mating area while females returned biennially during the mating season. However we did not observe any copulation events or other signs of mating behaviour and further studies would be needed to ascertain if this aggregation facilitates reproduction in zebra sharks.

All our observations of zebra sharks were conducted in daylight hours and the sharks were either resting on the substratum or swimming slowly in mid-water around the aggregation site. Zebra sharks are considered nocturnal feeders (Compagno 2002), and formation of groups that take refuge in a small core area during daylight hours, then disperse for foraging in larger areas at dusk and night, is common in sharks (Klimley \& Nelson 1984, Economakis \& Lobel 1998, Sims et al. 2005). This group formation may be an anti-predatory tactic while resting (Semeniuk \& Dill 2005); it may facilitate social interaction and/or the location may act as a geographic landmark from which to forage (Klimley \& Nelson 1984). Further research including localised movement, diet analyses and analysis of the reproductive cycle and mating is required to understand the function of this aggregation. 


\section{Assumptions of mark-recapture models}

$$
\text { Photo-ID validation }
$$

In this study we successfully used photo-ID of natural markings on adult zebra sharks to estimate population parameters with mark-recapture methods. Mark-recapture methods assume that markings are unique and do not change over time (Pollock et al. 1990). The use of conventional tagging combined with photo-ID showed that natural marks are unique to individuals and persist for at least $4 \mathrm{yr}$ in this population of wild adult zebra sharks. The zebra sharks aggregating at The Group are all large spotted adults that have most likely completed their ontogenetic pigment changes from the striped juvenile phase. As in whale sharks, adult zebra sharks are highly patterned (Meekan et al. 2006) and an incremental loss of a small number of spots is unlikely to cause difficulty with individual identification. The sole use of conventional dart-tags, however, was problematic. We found heavy fouling on the dart-tags after only a few months of deployment making it difficult to read the tag number in situ without restraining the shark or removing the tag. Further, we found an approximate $17 \%$ dart-tag loss over the duration of the study (up to $744 \mathrm{~d}$ ). Although this degree of dart-tag loss is smaller than for some other shark species (e.g. Xiao et al. 1999; school shark Galeorhinus galeus $41 \%$ per year, gummy shark Mustelus antarticus $63 \%$ per year), tag shedding may lead to an overestimation in population abundance. It is unknown whether pigmentation patterns will remain constant for longer durations and only through monitoring tagged animals in the wild will we be able to assess the use of photo-ID methods extending beyond the duration of this 3 yr study.

\section{Survival rates constant between individuals}

Both robust design and JS models assume all individuals within each sex have equal survival probabilities. This assumption is unlikely to be violated as mortality rates tend to be low for adult sharks as most predation occurs at the smaller juvenile stages (Cortés 2004). Throughout the study there was evidence of only one attempted predation event, where a female shark was observed with a larger heterospecific sharkbite scar on her abdomen. There is currently no known information on predation on adult zebra sharks.

\section{Closure assumption}

The robust design assumes that the population remains demographically closed within the annual pri- mary periods. Additions and deletions due to births and deaths are highly unlikely as no juveniles were sighted at any time and survival rates were high between primary periods, with multiple individuals being repeatedly sighted among both primary and secondary periods. The closure assumption also requires the population to be closed to immigration and emigration within the primary periods, and this is likely to have been violated as at any one time the number of zebra sharks at The Group was smaller than the total number calculated visiting The Group over the annual aggregation season. However the assumption can be relaxed if there is no overall net change to the population during the closure period: i.e. if movement into and out of the study area occurs randomly, the estimates should not be biased (Kendall 1999). Preliminary data from acoustic tagging of zebra sharks over the aggregation period show random movement into and out of The Group, supporting this closure assumption (unpubl. data), though the temporal change in sex-ratio, indicating that males arrive before females during the aggregation period, suggest otherwise. To assess the potential resulting bias we also modelled abundance with the JS model which relaxes the closure assumption. The mean abundance estimates for the JS model were larger than those for the robust design, though the error margins and 95\% confidence intervals overlap indicting minimal bias in the estimates.

\section{Model performance and comparison of open and closed models}

The estimates between the robust design and JS models are not directly comparable as the JS model requires the data to be pooled over the primary periods, and assumes that sampling is instantaneous (Pollock et al. 1990), which is highly likely to be violated in this case as sampling occurred during a 4 to 6 mo period. Further, there was strong support in the robust design that capture probabilities varied by secondary sample; however, it was not possible to model time variant capture probabilities in the JS model due to inestimable parameters. As such, survey effort could not be incorporated into the JS model and as individual covariates also cannot be modelled (White \& Burnham 1999), the JS model set was much smaller and the abundance estimates contained greater variation due to the model than for the robust design. When the assumptions are met or violation of assumptions does not result in bias, the robust design is the preferable model as there is less confounding in parameter estimation, data are maximised through the use of more time intervals, time covariates as well as individual covariates. To minimise violations of the closure 
assumption within the robust design, further information on the extent of movement of individual zebra sharks outside of the study area during the aggregation period would be informative for re-designing the experiment with respect to sampling interval and location. Such information could be obtained through satellite telemetry and more extensive mark-recapture surveys at regional locations.

In summary, we have presented the first abundance estimates for an aggregation of zebra sharks. While the aggregation is biased towards females and partly sexually segregated temporally, the role and significance of this aggregation is not known. Indeed, apart from some data on species range, little is known about population structure or individual movements for this species in Australia and globally. In addition to describing a local aggregation, this study provides validation of photo-ID as a research tool that can be used to extend the current study temporally and spatially to further explore the ecology of this species. Furthermore, predictable visitation of large, presumably mature individuals to the site raises conservation concerns if aggregations of similar size and structure occur in regions where zebra sharks are fished.

Acknowledgements. We thank numerous field assistants, in particular: R. Slade, R. Dunlop, J. Kreuger, J. Smith, M. Kospartov, J. White, P. Quayle, B. Tillett, B. Yarrow and D. Paton. Thanks to D. Bell for information on his previous zebra shark tagging study and D. Perrine for providing the archival photograph. Thanks to D. Pavlacky and S. Blomberg for invaluable assistance with analyses. This study was supported by grants from the Winifred Violet Scott Foundation, the Australia and Pacific Science Foundation and a University of Queensland scholarship to C.L.D. We thank the Moreton Bay Research Station and Manta Lodge YHA and Scuba Centre for in-kind support. All research was conducted with approval from the University of Queensland Animal Ethics Committee (\# ZOO/ENT/490/05) and the Department of Primary Industries and Fisheries (General Fisheries Permit \# PRM03978K).

\section{LITERATURE CITED}

Allaby M (2006) A Dictionary of ecology. Oxford University Press, Oxford

Bradford AL, Wade PR, Weller DW, Burdin AM and others (2006) Survival estimates of western gray whales Eschrichtius robustus incorporating individual heterogeneity and temporary emigration. Mar Ecol Prog Ser 315: 293-307

Bradshaw CJA, Mollet HF, Meekan MG (2007) Inferring population trends for the world's largest fish from mark-recapture estimates of survival. J Anim Ecol 76: 480-489

Buckland ST (1990) Estimation of survival rates from sightings of individually identifiable whales. Rep Int Whal Comm Spec Issue 12:149-153

Burnham KP, Anderson DR (2002) Model selection and multimodel inference: a practical information-theoretic approach, 2nd edn. Springer-Verlag, New York
Castro ALF, Rosa RS (2005) Use of natural marks on population estimates of the nurse shark, Ginglymostoma cirratum, at Atol das Rocas Biological Reserve, Brazil. Environ Biol Fishes 72:213-221

Clarke TA (1971) The ecology of the scalloped hammerhead shark, Sphyrna lewini, in Hawaii. Pac Sci 25:133-144

Cliff G, van Der Elst RP, Govender A, Witthuhn TK, Bullen EM (1996) First estimates of mortality and population size of white sharks on the South African coast. In: Klimley AP, Ainley DG (eds) Great white sharks: the biology of Carcharodon carcharias, Vol 1. Academic Press, San Diego, CA, p 393-400

Compagno LJV (ed) (2002) Sharks of the world. An annotated and illustrated catalogue of shark species known to date. Vol 2. Bullhead, mackerel and carpet sharks (Heterodontiformes, Lamniformes and Orectolobiformes). FAO, Rome

Compagno L, Dando M, Fowler S (2005) Sharks of the world. Princeton University Press, Princeton and Oxford

Cormack RM (1964) Estimates of survival from the sighting of marked animals. Biometrika 51:429-438

Cortés E (2004) Life history patterns, demography, and population dynamics. In: Carrier JC, Musick JA, Heithaus MR (eds) Biology of sharks and their relatives. CRC Press, Boca Raton, FL, p 449-469

Dingerkus G (1986) Interrelationships of Orectolobiform sharks (Chondrichthyes: Selachii). In: Uyeno T, Arai R, Taniuchi T, Matsuura K (eds) Indo-Pacific fish biology: Proceedings of the Second International Conference on Indo-Pacific fishes. Ichthyological Society of Japan, Tokyo, p 227-245

> Dinsmore SJ, White GC, Knopf FL (2005) Mountain plover population responses to black-tailed prairie dogs in Montana. J Wildl Manage 69:1546-1553

Domeier ML, Colin PL (1997) Tropical reef fish spawning aggregations: defined and reviewed. Bull Mar Sci 60: $698-726$

> Domeier ML, Nasby-Lucas N (2007) Annual re-sightings of photographically identified white sharks (Carcharodon carcharias) at an eastern Pacific aggregation site (Guadalupe Island, Mexico). Mar Biol 150:977-984

- Economakis AE, Lobel PS (1998) Aggregation behavior of the grey reef shark, Carcharhinus amblyrhynchos, at Johnston Atoll, Central Pacific Ocean. Environ Biol Fishes 51: 129-139

> Friedlaender AS, Halpin PN, Qian SS, Lawson GL, Wiebe PH, Thiele D, Read AJ (2006) Whale distribution in relation to prey abundance and oceanographic processes in shelf waters of the Western Antarctic Peninsula. Mar Ecol Prog Ser 317:297-310

> Gordon I (1993) Pre-copulatory behavior of captive sandtiger sharks, Carcharias taurus. Environ Biol Fishes 38:159-164

Hammond PS (1986) Estimating the size of naturally marked whale populations using capture-recapture techniques. Rep Int Whal Comm Spec Issue 8:253-282

> Heupel MR, Simpfendorfer CA (2005) Quantitative analysis of aggregation behavior in juvenile blacktip sharks. Mar Biol 147:1239-1249

Hight BV, Lowe CG (2007) Elevated body temperatures of adult female leopard sharks, Triakis semifasciata, while aggregating in shallow nearshore embayments: evidence for behavioral thermoregulation? J Exp Mar Biol Ecol 352: $114-128$

Hueter RE, Heupel MR, Heist EJ, Keeney DB (2005) Evidence of philopatry in sharks and implications for the management of shark fisheries. J Northwest Atl Fish Sci 35: 239-247

> Huggins RM (1989) On the statistical analysis of cature experiments. Biometrika 76:133-140 
Jolly GM (1965) Explicit estimates from capture-recapture data with both death and immigration-stochastic model. Biometrika 52:225-247

Kendall WL (1997) Erratum: estimating temporary emigration using capture-recapture data with Pollock's robust design. Ecology 78:2248-2248

Kendall WL (1999) Robustness of closed capture-recapture methods to violations of the closure assumption. Ecology 80:2517-2525

Kendall WL, Pollock KH (2001) The robust design in capturerecapture studies: a review and evaluation by Monte Carlo simulation. In: McCullough DR, Barrett RH (eds) Wildlife 2001: populations. Elsevier Applied Science, Oakland, CA, p 31-43

Kendall WL, Pollock KH, Brownie C (1995) A likelihoodbased approach to capture-recapture estimation of demographic parameters under the robust design. Biometrics 51:293-308

Klimley AP (1987) The determinants of sexual segregation in the scalloped hammerhead shark, Sphyrna lewini. Environ Biol Fishes 18:27-40

Klimley AP, Nelson DR (1984) Diel movement patterns of the scalloped Hammerhead Shark (Sphyrna lewini) in relation to El Bajo Espiritu Santo: a refuging central-position social system. Behav Ecol Sociobiol 15:45-54

Kohler NE, Turner PA (2001) Shark tagging: A review of conventional methods and studies. Environ Biol Fishes 60: 191-223

Last PR, Stevens JD (1994) Sharks and rays of Australia. CSIRO Division of Fisheries, Melbourne

McKibben JN, Nelson DR (1986) Patterns of movement and grouping of grey reef sharks, Carcharinus amblyrhynchos, at Enewetak, Marshall Islands. Bull Mar Sci 38: 89-110

McLaughlin RH, O'Gower AK (1971) Life history and underwater studies of a heterodont shark. Ecol Monogr 41:271-289

Meekan MG, Bradshaw CJA, Press M, McLean C, Richards A, Quasnichka S, Taylor JG (2006) Population size and structure of whale sharks Rhincodon typus at Ningaloo Reef, Western Australia. Mar Ecol Prog Ser 319:275-285

Minta S, Mangel M (1989) A simple population estimate based on simulation for capture-recapture and captureresight data. Ecology 70:1738-1751

Nelson DR, Johnson RH (1980) Behaviour of the reef sharks of Rangiroa, French Polynesia. Nat Geogr Soc Res Rep 12: 479-498

> Newlands NK, Lutcavage ME, Pitcher TJ (2006) Atlantic bluefin tuna in the Gulf of Maine. I. Estimation of seasonal abundance accounting for movement, school and schoolaggregation behaviour. Environ Biol Fishes 77:177-195

Osgood KE, Checkley DM (1997) Seasonal variations in a deep aggregation of Calanus pacificus in the Santa Barbara Basin. Mar Ecol Prog Ser 148:59-69

Otis DL, Burnham KP, White GC, Anderson DR (1978) Statistical inference from capture data on closed animal populations. Wildl Monogr 62

Pillans RD, Simpfendorfer CA (2003) Zebra shark, Stegostoma fasciatum (Hermann, 1783). In: Cavanagh RD, Kyne PM, Fowler SL, Musick JA, Bennet MB (eds) The conservation status of Australiasian chondricthyans: Report of the IUCN Shark Specialist Group Australia and Oceania Regional Red List Workshop. IUCN, Queensland, p 60-61

Pollock KH, Nichols JD, Brownie C, Hines JE (1990) Statistical-inference for capture-recapture experiments. Wildl Monogr 107:1-97

Pradel R (1996) Utilization of capture mark-recapture for the study of recruitment and population growth rate. Biometrics 52:703-709
Pratt HL Jr, Carrier JC (2001) A review of elasmobranch reproductive behavior with a case study on the nurse shark, Ginglymostoma cirratum. Environ Biol Fishes 60: 157-188

R Development Core Team (2004) R: a language and environment for statistical computing. R Foundation for Statistical Computing, Vienna

Sadovy Y, Domeier M (2005) Are aggregation-fisheries sustainable? Reef fish fisheries as a case study. Coral Reefs 24:254-262

Sampedro MP, Gonzalez-Gurriaran E (2004) Aggregating behaviour of the spider crab Maja squinado in shallow waters. J Crustac Biol 24:168-177

Schwarz CJ, Arnason AN (1996) A general methodology for the analysis of capture-recapture experiments in open populations. Biometrics 52:860-873

Seber GAF (1965) A note on the multiple-recapture census. Biometrika 52:249-259

Semeniuk CAD, Dill LM (2005) Cost/benefit analysis of group and solitary resting in the cowtail stingray, Pastinachus sephen. Behav Ecol 16:417-426

Sims D, Nash J, Morritt D (2001) Movements and activity of male and female dogfish in a tidal sea lough: alternative behavioural strategies and apparent sexual segregation. Mar Biol 139:1165-1175

Sims DW, Southall EJ, Wearmouth VJ, Hutchinson N, Budd GC, Morritt D (2005) Refuging behaviour in the nursehound Scyliorhinus stellaris (Chondrichthyes: Elasmobranchii): preliminary evidence from acoustic telemetry. J Mar Biol Assoc UK 85:1137-1140

Smith TG, Martin AR (1994) Distribution and movements of belugas, Delphinapterus leucas, in the Canadian high arctic. Can J Fish Aquat Sci 51:1653-1663

Sourisseau M, Simard Y, Saucier FJ (2006) Krill aggregation in the St. Lawrence system, and supply of krill to the whale feeding grounds in the estuary from the gulf. Mar Ecol Prog Ser 314:257-270

Speed CW, Meekan MG, Bradshaw CJA (2007) Spot the match - wildlife photo-identification using information theory. Front Zool 4:2

Strong WRJ, Bruce BD, Nelson DR, Murphy RD (1996) Population dynamics of white sharks in Spencer Gulf, South Australia. In: Klimley AP, Ainley DG (eds) Great white sharks: the biology of Carcharodon carcharias. Academic Press, San Diego, CA, p 401-414

Van Tienhoven AM, Den Hartog JE, Reijns RA, Peddemors VM (2007) A computer-aided program for patternmatching of natural marks on the spotted raggedtooth shark Carcharias taurus. J Appl Ecol 44:273-280

White GC, Burnham KP (1999) Program MARK: survival estimation from populations of marked animals. Bird Study 46:120-139

Williams BK, Nichols JD, Conroy MJ (2002) Analysis and management of animal populations: modeling, estimation, and decision making. Academic Press, San Diego

Wilson SG, Taylor JG, Pearce AF (2001) The seasonal aggregation of whale sharks at Ningaloo reef, western Australia: currents, migrations and the El Nino/Southern oscillation. Environ Biol Fishes 61:1-11

Xiao Y, Brown LP, Walker TI, Punt AE (1999) Estimation of instantaneous rates of tag shedding for school shark, Galeorhinus galeus, and gummy shark, Mustelus antarcticus, by conditional likelihood. Fish Bull 97: 170-184

> Young CM, Tyler PA, Cameron JL, Rumrill SG (1992) Seasonal breeding aggregations in low-density populations of the bathyal echinoid Stylocidaris lineata. Mar Biol 113: 603-612 
Appendix 1. Stegostoma fasciatum. Complete list of 63 robust design models. AICc = Akaike information criterion for small samples; delta $\mathrm{AICC}=$ difference in the AICc of a model from the minimum AICc model; $\mathrm{AICc}$ weight $=$ Akaike weight used in model averaging; $\varphi=$ apparent survival; $\gamma=$ temporary emigration; $\mathrm{p}=$ capture probability; $()=$. time constant; $t=$ time varying by secondary sample; $g=$ sex; Ran $=$ random temporary emigration; $0=$ no temporary emigration; $R e s=$ residency; Eff $=$ efficiency; $T=$ trend over time by secondary sample

\begin{tabular}{|c|c|c|c|c|}
\hline Model & $\mathrm{AICc}$ & Delta AICc & AICc weight & No. parameters \\
\hline$\varphi(.) \gamma(0) \mathrm{p}(g+t)$ & 1730.38 & 0.00 & 0.36678 & 16 \\
\hline$\varphi(g) \gamma(0) \mathrm{p}(g+t)$ & 1732.40 & 2.02 & 0.13369 & 17 \\
\hline$\varphi(.) \gamma(\operatorname{Ran}) \mathrm{p}(g+t)$ & 1732.48 & 2.10 & 0.12819 & 17 \\
\hline$\varphi(t) \gamma(0) \mathrm{p}(g+t)$ & 1732.48 & 2.10 & 0.12813 & 17 \\
\hline$\varphi(g+t) \gamma(0) \mathrm{p}(g+t)$ & 1734.42 & 4.04 & 0.04858 & 18 \\
\hline$\varphi(g) \gamma(\operatorname{Ran}) \mathrm{p}(g+t)$ & 1734.50 & 4.12 & 0.04667 & 18 \\
\hline$\varphi(.) \gamma(0) \mathrm{p}(g+t+\operatorname{Res})$ & 1734.58 & 4.20 & 0.04500 & 19 \\
\hline$\varphi(.) \gamma(g+\operatorname{Ran}) \mathrm{p}(g+t)$ & 1734.61 & 4.23 & 0.04428 & 18 \\
\hline$\varphi(g) \gamma(0) \mathrm{p}(g+t+R e s)$ & 1736.43 & 6.05 & 0.01782 & 20 \\
\hline$\varphi(t) \gamma(0) \mathrm{p}(g+t+R e s)$ & 1736.54 & 6.16 & 0.01688 & 20 \\
\hline$\varphi(g) \gamma(g+R a n) \mathrm{p}(g+t)$ & 1736.63 & 6.25 & 0.01610 & 19 \\
\hline$\varphi(g+t) \gamma(0) \mathrm{p}(g+t+R e s)$ & 1738.44 & 8.06 & 0.00651 & 21 \\
\hline$\varphi(.) \gamma(0) \mathrm{p}(t)$ & 1742.91 & 12.53 & 0.00070 & 13 \\
\hline$\varphi(t) \gamma(0) \mathrm{p}(t)$ & 1744.67 & 14.28 & 0.00029 & 14 \\
\hline$\varphi(.) \gamma(\operatorname{Ran}) \mathrm{p}(t)$ & 1745.02 & 14.64 & 0.00024 & 14 \\
\hline$\varphi(.) \gamma(0) \mathrm{p}(t+R e s)$ & 1746.99 & 16.60 & 0.00009 & 16 \\
\hline$\varphi(t) \gamma(0) \mathrm{p}(t+R e s)$ & 1748.82 & 18.44 & 0.00004 & 17 \\
\hline$\varphi(.) \gamma(0) \mathrm{p}(g+E f f+R e s)$ & 1891.59 & 161.21 & 0.00000 & 5 \\
\hline$\varphi(.) \gamma(0) p(g+T+E f f+R e s)$ & 1892.37 & 161.99 & 0.00000 & 6 \\
\hline$\varphi(t) \gamma(0) \mathrm{p}(g+E f f+R e s)$ & 1893.01 & 162.63 & 0.00000 & 6 \\
\hline$\varphi(g) \gamma(0) \mathrm{p}(g+E f f+R e s)$ & 1893.64 & 163.26 & 0.00000 & 6 \\
\hline$\varphi(t) \gamma(0) \mathrm{p}(g+T+E f f+R e s)$ & 1894.31 & 163.93 & 0.00000 & 7 \\
\hline$\varphi(g) \gamma(0) \mathrm{p}(g+T+E f f+R e s)$ & 1894.42 & 164.04 & 0.00000 & 7 \\
\hline$\varphi(g+t) \gamma(0) \mathrm{p}(g+E f f+R e s)$ & 1895.06 & 164.68 & 0.00000 & 7 \\
\hline$\varphi(g+t) \gamma(0) \mathrm{p}(g+T+E f f+R e s)$ & 1896.37 & 165.99 & 0.00000 & 8 \\
\hline$\varphi(.) \gamma(0) p(g+E f f)$ & 1900.87 & 170.49 & 0.00000 & 4 \\
\hline$\varphi(.) \gamma(0) \mathrm{p}(g+T+E f f)$ & 1901.55 & 171.17 & 0.00000 & 5 \\
\hline$\varphi(t) \gamma(0) \mathrm{p}(g+E f f)$ & 1902.60 & 172.22 & 0.00000 & 5 \\
\hline$\varphi(.) \gamma(\operatorname{Ran}) \mathrm{p}(g+E f f)$ & 1902.88 & 172.50 & 0.00000 & 5 \\
\hline$\varphi(g) \gamma(0) \mathrm{p}(g+E f f)$ & 1902.89 & 172.51 & 0.00000 & 5 \\
\hline$\varphi(g) \gamma(0) \mathrm{p}(g+T+E f f)$ & 1903.59 & 173.21 & 0.00000 & 6 \\
\hline$\varphi(t) \gamma(0) \mathrm{p}(g+T+E f f)$ & 1903.60 & 173.22 & 0.00000 & 6 \\
\hline$\varphi(g+t) \gamma(0) \mathrm{p}(g+E f f)$ & 1904.61 & 174.23 & 0.00000 & 6 \\
\hline$\varphi(g) \gamma(R a n) \mathrm{p}(g+E f f)$ & 1904.91 & 174.53 & 0.00000 & 6 \\
\hline$\varphi(g+t) \gamma(0) \mathrm{p}(g+T+E f f)$ & 1905.65 & 175.27 & 0.00000 & 7 \\
\hline$\varphi(.) \gamma(0) \mathrm{p}(E f f+R e s)$ & 1905.81 & 175.43 & 0.00000 & 4 \\
\hline$\varphi(.) \gamma(0) \mathrm{p}(T+E f f+\operatorname{Res})$ & 1905.95 & 175.56 & 0.00000 & 5 \\
\hline$\varphi(t) \gamma(0) \mathrm{p}(E f f+R e s)$ & 1906.79 & 176.41 & 0.00000 & 5 \\
\hline$\varphi(g) \gamma(g+\operatorname{Ran}) \mathrm{p}(g+E f f)$ & 1907.18 & 176.80 & 0.00000 & 7 \\
\hline$\varphi(g+t) \gamma(R a n) \mathrm{p}(g+E f f)$ & 1907.19 & 176.81 & 0.00000 & 7 \\
\hline$\varphi(t) \gamma(0) \mathrm{p}(T+E f f+R e s)$ & 1907.74 & 177.35 & 0.00000 & 6 \\
\hline$\varphi(g+t) \gamma(g+R a n) p(g+E f f)$ & 1909.25 & 178.87 & 0.00000 & 8 \\
\hline$\varphi(.) \gamma(0) \mathrm{p}(E f f)$ & 1914.83 & 184.45 & 0.00000 & 3 \\
\hline$\varphi(.) \gamma(0) \mathrm{p}(T+E f f)$ & 1914.94 & 184.56 & 0.00000 & 4 \\
\hline$\varphi(t) \gamma(0) \mathrm{p}(E f f)$ & 1915.83 & 185.45 & 0.00000 & 4 \\
\hline$\varphi(t) \gamma(0) \mathrm{p}(T+E f f)$ & 1916.79 & 186.41 & 0.00000 & 5 \\
\hline$\varphi(.) \gamma(0) \mathrm{p}(g+T+R e s)$ & 1929.27 & 198.89 & 0.00000 & 5 \\
\hline$\varphi(t) \gamma(0) \mathrm{p}(g+T+R e s)$ & 1930.44 & 200.06 & 0.00000 & 6 \\
\hline$\varphi(g) \gamma(0) \mathrm{p}(g+T+R e s)$ & 1931.30 & 200.92 & 0.00000 & 6 \\
\hline$\varphi(g) \gamma(0) \mathrm{p}(T+R e s)$ & 1937.77 & 207.39 & 0.00000 & 5 \\
\hline$\varphi(.) \gamma(0) \mathrm{p}(g+T)$ & 1938.05 & 207.67 & 0.00000 & 4 \\
\hline$\varphi(t) \gamma(0) p(g+T)$ & 1938.49 & 208.11 & 0.00000 & 5 \\
\hline$\varphi(g+t) \gamma(0) \mathrm{p}(T+R e s)$ & 1939.26 & 208.88 & 0.00000 & 6 \\
\hline$\varphi(g) \gamma(0) \mathrm{p}(g+T)$ & 1940.08 & 209.70 & 0.00000 & 5 \\
\hline$\varphi(.) \gamma(0) \mathrm{p}(T+R e s)$ & 1941.59 & 211.21 & 0.00000 & 4 \\
\hline$\varphi(t) \gamma(0) p(T+R e s)$ & 1943.16 & 212.77 & 0.00000 & 5 \\
\hline$\varphi(g) \gamma(0) p(T)$ & 1946.87 & 216.49 & 0.00000 & 4 \\
\hline$\varphi(g+t) \gamma(0) p(T)$ & 1948.29 & 217.91 & 0.00000 & 5 \\
\hline$\varphi(.) \gamma(0) \mathrm{p}(T)$ & 1950.42 & 220.04 & 0.00000 & 3 \\
\hline$\varphi(t) \gamma(0) \mathrm{p}(T)$ & 1951.69 & 221.31 & 0.00000 & 4 \\
\hline$\varphi(.) \gamma(0) \mathrm{p}(g+R e s)$ & 1969.15 & 238.77 & 0.00000 & 4 \\
\hline$\varphi(g) \gamma(0) \mathrm{p}(g+\operatorname{Res})$ & 1971.12 & 240.74 & 0.00000 & 5 \\
\hline$\varphi(.) \gamma(0) \mathrm{p}(\operatorname{Res})$ & 1982.81 & 252.43 & 0.00000 & 2 \\
\hline
\end{tabular}

